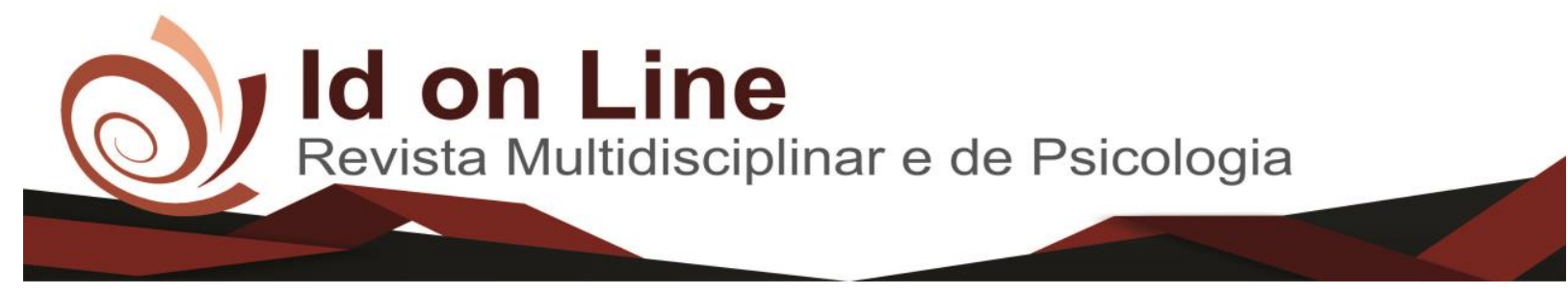

Comment

\title{
O planejamento como instrumento de gestão eficaz e eficiente: Uma análise do sistema educacional no município de Iguatu
}

\author{
Célia Maria Freitas Guedes Amorim ${ }^{1}$
}

\begin{abstract}
Resumo: O financiamento da educação é algo complexo. Uma espécie de sistema, cujas funções internas são desconhecidas e cujo funcionamento é compreendido mediante uma avaliação das relações entre valores de entrada (input) e de saída (output). Parece haver por parte dos educadores, um certo desconhecimento sobre os processos que envolvem os recursos direcionados à educação e suas formas de gestão.
\end{abstract}

Palavras-Chave: Gestão da educação. Planejamento. Sistema educacional.

\section{Planning as an effective and efficient management tool: An analysis of the educational system in the municipality of Iguatu}

\begin{abstract}
Education funding is complex. A kind of system whose internal functions are unknown and whose functioning is understood through an evaluation of the relations between input and output values. It seems that there is a certain lack of knowledge about the processes that involve resources directed to education, its forms of management.
\end{abstract}

Keywords: Education management. Planning. Educational system.

\section{Introdução}

Discutir sobre as políticas educacionais, envolve conhecer também as relações de poder estabelecidas entre o Estado, os indivíduos e a sociedade que se pretende estudar. Levase em conta que, um modelo de Estado implica em um modelo de educação, já que esta última evoca uma representação de homem e do mundo que se pretende formar.

\footnotetext{
${ }^{1}$ Doutora e mestre em Ciências da Educação, pela Universidade de San Carlos(2016).Possui graduação em PEDAGOGIA pela Universidade Estadual do Ceará (1997) e mestrado em Ciências da educação pela Universidade de San Carlos (2013). Atualmente é dedicação exclusiva do Instituto Federal de Educação,Ciência e Tecnologia-IFCE-Campus Iguatu, professora especialista - Secretaria da Educação do Governo do Estado do Ceará,Docente do Instituto Federal do Piauí, concursado do Instituto Federal do Piauí e dedicação exclusiva do INSTITUTO Federal de Educação Ciências e Tecnologia-Campus Iguatu. Tem experiência na área de Educação, com ênfase em Gestão Escolar, foco na Formação de Professores.No IFCE/ Campus Iguatu Coordena a Especialização em Educação Profissional e Tecnológica do IFCE-Iguatu.
} 
Segundo Giron (2008, p.2), “[...], a política educacional defendida por um determinado governo reflete como ele [Estado] entende o mundo e as relações que se estabelecem na sociedade".

Foi à partir da Constituição de 1934 (Art. 156) que, pela primeira vez, instituiu-se a vinculação de um orçamento para a educação, na época, obrigatório para as três esferas administrativas. Neste caso, à União e aos Municípios competia aplicar, pelo menos dez por cento. Aos Estados e ao Distrito Federal, competia a aplicação de vinte por cento de toda a renda obtida de impostos para a manutenção e desenvolvimento da educação (MELCHIOR, 1981). No caso do ensino rural, competiria ao Estado a aplicação de, no mínimo, vinte por cento do que fosse destinado à educação.

A vinculação de recursos para a educação foi historicamente expressa por meio de percentuais de aplicação obrigatória, estabelecidos em Constituições Federais, decretos e leis ao longo da história da educação brasileira (PINTO, 2000; OLIVEIRA, R., 2007; DUARTE; FARIA, 2010; ROSSINHOLI, 2010)

De acordo com a Constituição Federal de 1988 que instituiu o Plano Plurianual (PPA), a Lei de Diretrizes Orçamentária (LDO), a Lei Orçamentária Anual (LOA), todos estes instrumentos de planejamento estão vinculados diretamente. A LOA deve refletir as políticas e diretrizes orçamentárias constantes no PPA, bem como atender aos parâmetros que a lei de diretrizes orçamentária estabeleceu para sua elaboração.

Quanto à fase de planejamento existem obrigações e prazos constitucionais e legais para que os governos encaminhem os projetos à instância responsável pela avaliação dos mesmos.

O objetivo deste estudo é propor uma análise das políticas, que gerenciam diretamente o sistema educacional, de forma a elucidar algumas condições para sua eficiência e eficácia na gestão dos recursos financeiros.

Citamos a seguir, os instrumentos orçamentários público no Brasil, que englobam o planejamento orçamentário do setor educacional: 


\section{Plano Plurianual - PPA}

Trata dos objetivos e metas da administração como um todo, tem vigência de quatro anos (três na gestão atual do governante que construiu o documento e um na nova gestão). Deve ser enviado ao legislativo no final do mês de agosto do primeiro ano de mandato do executivo.

Nesse sentido o município de Iguatu cumpriu em todos os anos essa determinação legal e Câmara Municipal de Iguatu, também votou no prazo previsto e fez as mudanças que os vereadores consideraram necessárias. Destaque especial para a metodologia de elaboração do PPA que aconteceu de forma participativa, e em um Seminário no ano de 2005 a população pode pela primeira vez dar a sua opinião na construção deste instrumento de gestão eficaz no processo de descentralização administrava, a pasta da Educação teve uma sala especial e a oficina sobre a educação contou com a participação de professores, alunos, gestores, pais e funcionários escolhidos entre seus pares.

No segundo mandato de gestão, após quatro anos de muito trabalho, a equipe já detinha o conhecimento dos processos, em especial os gestores, então para construção do segundo PPA teve uma maior participação, visto que a Equipe da Secretaria de Administração Finanças e Planejamento realizaram oficinas itinerantes na zona rural e urbana, discutindo em cada comunidade os seus anseios, isso permitiu a construção do Programa Cidade do Futuro que é um planejamento estratégico que planejou o município para vinte anos, esse planejamentos garantiu ao município uma maior agilidade na captação de recursos, pois já sabendo aonde se quer chegar fica mais fácil trilhar os caminhos.

$\mathrm{Na}$ investigação documental percebeu-se que o PPA do município de Iguatu-Ceará define as diretrizes, ou seja, um conjunto de critérios de ação e de decisão que orientam e disciplinam o processo de gestão, nele está descrito os objetivos macro de cada política que permite a realização das ações e definida as metas, que são os objetivos traduzidos em números, ou seja, quantidade física e monetária do que o município pretende obter, quanto gastará em obras, equipamentos e programas sociais.

No PPA do ano de 2005 o plano está orientado em duas linhas centrais:

a) A ampliação do número de matrícula. Nesse sentido a redução do déficit está prevista que ocorrerá com o aumento de salas e de professores, bem como com a 
ampliação da rede escolar, até as localidades mais carentes, onde não existam equipamentos ou que estejam em estado precário, requerendo recuperação.

b) A melhoria da qualidade do ensino, nesse sentido o plano prevê que o ensino deve passar por uma análise que leve a melhoria da qualidade do currículo, das razões da competência, da reciclagem dos professores e de melhorias nas condições de trabalho, consolidando um sistema educacional que evite desperdício e forme um jovem para o exercício da cidadania.

No segundo PPA $(2009$, p.) houve uma ampliação das linhas de ação, citadas a seguir:

a) Melhoria da estrutura física e equipamentos educacionais das unidades escolares;

b) Assistência estruturante aos estudantes;

c) Formação dos Profissionais da Educação;

d) Garantia de Transporte escolar para os alunos;

e) Ampliação do atendimento a Educação Infantil;

f) Universalização do atendimento ao Ensino Fundamental;

g) Melhorar a qualidade da alimentação escolar;

h) Implantação da gestão participativa na educação;

i) Aperfeiçoamento da Educação de Jovens Adultos;

j) Ampliação do atendimento educacional especializado a pessoas com necessidades educacionais.

\section{Lei de Diretrizes Orçamentárias - LDO}

Esta lei é um instrumento construído anualmente, que trata das prioridades para o orçamento do ano seguinte é encaminhada ao poder Legislativo até 15 de abril de cada ano, conforme determina a Lei Orgânica Municipal.

A LDO tem como documento base o PPA e orienta a elaboração do orçamento do ano subsequente, lá estão estabelecidos percentuais da receita arrecada cria condições aos gestores observar os limites fixados para receitas e despesas para o exercício financeiro.

Neste instrumento estão previstos as mudanças na legislação tributária, caso a administração resolva introduzir aumento, redução ou isenção na cobrança de qualquer imposto da competência municipal, bem como as mudanças na política salarial e de pessoal 
ou nos critérios para reajustes salarias e para contratação de novos funcionários por concursos, esse fato foi encontrado na LDO de 2010 e 2011.

A Lei Orçamentária Anual (LOA) é uma peça elaborada pelo Poder Executivo é o orçamento propriamente dito, nele estão contidos os programas, subprogramas, projetos e as atividades que indicam metas e prioridades que foram estabelecidas na LDO, bem como os recursos necessários para o seu cumprimento, é o documento que define as fontes de receita e autoriza às despesas municipais, os valores estão expresso, sendo detalhado por órgão do governo municipal.

O Executivo envia ao Legislativo até o dia 31 de agosto de cada ano. Caso o Executivo perca o prazo a Comissão de Orçamento da Câmara elabora uma proposta, em Iguatu-Ceará no período da pesquisa o governo municipal nunca perdeu prazos, cumpriu o estabelecido pela Lei Orgânica Municipal.

O Plano Nacional, o Estadual e o Plano Municipal de Educação deverão está relacionado ao PPA, LDO e LOA de cada ente federado, a previsão das despesas deverão ser planejadas a curto, médio e longo prazo através dos instrumentos de gestão.

\section{A Lei Orçamentária Anual - LOA}

A Lei Orçamentária Anual retrata os valores e as metas, os objetivos e as prioridades estabelecidas nas duas leis anteriores, deve ser encaminhada ao legislativo até 30 de setembro de cada ano.

O orçamento está fundamentado na transparência orçamentária e respeita os princípios básicos da unidade, equilíbrio, universalidade, publicidade, anualidade, clareza. No município de Iguatu-CE o modelo de construção é de forma participativa, o conselho do orçamento organiza anualmente as reuniões territoriais que discute com a comunidade o orçamento do ano seguinte, o controle social do orçamento é feito por esse conselho, além dos conselhos das políticas setoriais.

A peça orçamentária tem uma padronização nacional, com as peculiaridades locais, de acordo com a Lei $4320 / 64$ os projetos e atividades devem ser classificados em: 
Quadro 01 - Quadro dos projetos e atividades da LOA - Leis Orçamentária Anual

\begin{tabular}{|c|l|}
\hline FUNÇÃO & $\begin{array}{l}\text { Representa o maior nível de agregação das diversas áreas da despesa } \\
\text { do setor público, a educação é a função 12. }\end{array}$ \\
\hline SUBFUNÇÃO & $\begin{array}{l}\text { Agrega as ações de acordo com sua natureza básica, nesse caso em } \\
\text { relação à educação, deve está explicito os Programas, Subprogramas } \\
\text { e Unidades Orçamentárias. }\end{array}$ \\
\hline
\end{tabular}

Fonte: DOU n ${ }^{\circ}$ 15/04/1999.

O artigo $1^{\circ}$ da Portaria $n^{\circ} 42$, de 14 de abril de 1999, DOU $n^{\circ} 15 / 04 / 1999$, estabelece no artigo $1^{\circ}$, parágrafo $1^{\circ}$ que como função deve entender-se o maior nível de agregação às diversas áreas das despesas que competem ao setor público, a subfunção representa uma partição da função, visando agregar determinado subconjunto de despesa do setor público.

Para efeito desta portaria, entende-se por:

a) Programa - o instrumento de organização da ação governamental visando à concretização dos objetivos pretendidos, sendo mensurados por indicadores estabelecidos no plano plurianual;

b) Projeto - um instrumento de programação para alcançar o objetivo de um programa;

c) Atividade - é um instrumento de programação para alcançar o objetivo de um programa, de modo contínuo e permanente, manutenção das ações de governo.

d) Operações especiais- as despesas que não contribuem para manutenção das ações de governo são os bens ou serviços adquiridos. (artigo $1^{\circ}$ da Portaria $n^{\circ} 42$, de 14 de abril de 1999, DOU n 15/04/1999)

No caso da Política de educação a função e subfunções orçamentárias estão assim instituídas:

Quadro 02 - Instituição orçamentárias funções e subfunções de governo

\begin{tabular}{|c|l|l|}
\hline FUNÇÃO & 12 & EDUCAÇÃ̃O \\
\hline \multirow{4}{*}{ SUBFUNÇÃO } & 361 & ENSINO FUNDAMENTAL \\
\cline { 2 - 3 } & 365 & EDUCAÇÃO INFANTIL \\
\cline { 2 - 3 } & 366 & EDUCAÇÃO DE JOVENS E ADULTOS \\
\cline { 2 - 3 } & 367 & EDUCAÇÃO ESPECIAL \\
\cline { 2 - 3 } & 363 & ENSINO PROFISSIONAL \\
\cline { 2 - 3 } & 362 & ENSINO MÉDIO \\
\cline { 2 - 3 } & 364 & ENSINO SUPERIOR \\
\hline
\end{tabular}

Fonte: DOU n ${ }^{\circ}$ 15/04/1999. 
As subfunções 361, 365, 366 e 367 são objetos de obrigatoriedade da educação Municipal, já a subfunção 362 é prioridade do Estado já a 363 e 364 são prioridade da União, no país tem se notado uma ação conjunta com objetivo de universalizar Educação Infantil, Ensino Médio e a redução do analfabetismo com o fortalecimento da Educação de Jovens e Adultos, bem como a implantação da escola inclusiva com a implementação do Atendimento educacional especializado. O ensino Profissionalizante e Superior tem sido meta do governo Federal em parceria com os Estados e Municípios.

O Instrumento de planejamento da educação Municipal é o Plano Municipal de Educação buscando compreender como são tratados os recursos humanos e financeiros, compreendendo-o como um instrumento eficaz e eficiente de gestão e está vinculado com os instrumentos de gestão e a legislação vigente.

A construção do Plano foi realizada de forma democrática e participativa, visto que foram realizados 47 fóruns escolares e Fórum Municipal que consolidou as deliberações, o Plano Municipal de Educação foi concebido a partir dos objetivos e metas definidas no Plano Plurianual, os dois documentos foram elaborados no ano de 2005 e 2009.

Na fala do Prefeito Municipal de Iguatu Agenor Gomes de Araújo Neto (2009), ele afirma:

\footnotetext{
Uma das prioridades essenciais da nossa gestão tem sido a educação, que tem sido fomentada através da valorização dos educadores e da implementação de um plano que pensa a educação através do seu aspecto universal e libertado, preceito afirmado no Plano Municipal de educação, isso demonstra a intenção da municipalidade em garantir a formação dos profissionais da educação, fato gerador da nossa investigação, pois pensar no capital humano. é pensar nas pessoas como investidores e seres em constante formação, sua valorização é sem dúvida a garantia da qualidade o trabalho.
}

No Plano municipal define-se como objetivo geral a garantia do funcionamento da rede municipal de ensino a partir de padrões básicos mediante a integração das ações do poder público visando o fortalecimento da autonomia da escola e a melhoria da qualidade de ensino.

A gestão municipal criou o Programa Cidade do Futuro, porém ela somente poderá ser sustentável através da educação, e a educação para transformar tem que antes de tudo pensar nas pessoas que a fazem. A investigação analisará a remuneração e o aperfeiçoamento oferecido aos profissionais da educação em Iguatu. 
$\mathrm{Na}$ prática a efetivação dos padrões básicos de qualidade tem sido garantida, o município possui um Programa denominado Cidade do Futuro onde prevê um planejamento de gestão para vinte anos, nota-se a qualidade da infraestrutura das escolas municipais que tem passado por reformas, ampliações e construções, em especial a educação infantil na construção de cinco creches, PROINFÂNCIA (Programa Nacional de Reestruturação e Aquisição de Equipamentos para a Rede Escolar Pública de Educação Infantil (Proinfância), criado pelo governo federal e instituído pela resolução $\mathrm{n}^{\circ} 6$, de 24 de abril de 2007), importante destacar o controle de qualidade dos equipamentos e mobiliários de grande parte das escolas municipais, tanto na zona rural, quanto na zona urbana.

No Plano Municipal estão prevista as PRIORIDADES da educação deste ente federativo:

1- Assegurar padrões básicos de funcionamento das Instituições da educação Municipal;

2- Promover a valorização dos Profissionais da educação;

3- Promover a autonomia da Gestão escolar, através da implementação de ações descentralizadora e democrática;

4- Modernizar a estrutura de ensino na rede municipal;

5- Institucionalizar sistema moderno de Avaliação na rede educacional para fortalecer o processo de ensino-aprendizagem;

6- Elevar o desempenho acadêmico dos alunos;

7- Fortalecer a gestão da escola;

8- Implementar ações para melhorar o gerenciamento dos recursos financeiros na escola;

9- Construir um ambiente harmônico no espaço escolar, a fim de promover a integração escola-família-comunidade.

$\mathrm{Na}$ visita as escolas, ficou claro essa busca de construção da qualidade da educação e o trabalho focado nas prioridades definidas, em especial no aspecto Pedagógico, Participativo e Articulador da educação Municipal que são sem dúvida os pontos mais forte da gestão municipal em educação.

Além das prioridades o plano estabelece as estratégias e metas a serem alcançadas tudo atrelado as prioridades do PPA e do próprio plano municipal da educação.

O plano não faz referência às fontes de recursos financeiros nem na questão financeira da educação, não estão previsto receitas, nem despesas essa é uma grande fragilidade detectada na pesquisa que confirma a hipótese de que os educadores não detêm conhecimento sobre o financiamento da educação. 


\section{Considerações finais}

Ao que indica a literatura, a evolução de todo processo orçamentário, denota uma prática acerca da administração pública orientada por instituições e valores econômicos, políticos e sociais vigentes em um determinado momento da história. Nesse contexto, a administração pública, muito mais do que a sua composição interna, é que vai determinar o seu funcionamento e sua capacidade de inovação e transformação. As forças econômicas, políticas e sociais parecem definir as premissas para as bases estruturais técnicas internas, que darão o sustentáculo para a formulação de métodos e modelos de planejamento para a elaboração dos futuros planos e orçamentos, conforme as circunstâncias políticas vigentes. Este pensamento está alinhado com Bouckeart (2002), quando orienta que o processo orçamentário, não parece algo separado de um contexto mais amplo. Vê-se pois, que a orientação dos sistemas orçamentários são sujeitos à modernização, conforme as mudanças sociais e políticas que possam interferir na sua gestão, controle e definição de responsabilidades.

Um aprofundamento nos dados encontrados, nos leva a crer que todos os atos rotineiros dos gestores que movem o sistema educacional do município de Iguatu, devem ser verificados e avaliados em um constante e ininterrupto método de consequências de atos, inserindo grupos de estudos mais elaborados, técnicos para verificar se há coerência entre recursos, não ficando somente a cargo de órgãos auditores e fiscalizadores.

Em resumo, diante do exposto, pode-se concluir que, é do protagonismo e do compromisso com que cada um dos indivíduos, atores do processo educacional, engajados política e criticamente, que poderemos vislumbrar políticas de financiamento da educação mais adequadas e descentralizadas, as quais resultarão em uma gestão compartilhada do ensino, que conduza a um padrão democrático e, portanto mais saudável.

\section{Referências}

BOUCKAERT, Geert. Reform of Budgetary Systems in the Public Sector. In: M. Hôgye (Org.) Local Government Budgeting. Budapest: LGI, 2002. pp.19-41. 
DUARTE, Marisa Ribeiro Teixeira.; FARIA, Geniana Guimarães. Recursos públicos para escolas públicas: as políticas de financiamento da Educação Básica no Brasil e a regulação do Sistema Educacional Federativo. Belo Horizonte: RHJ/FAE da UFMG, 2010.

GIRON, Graziela Rossetto. Desafios políticos para educação. Travessias, Cascavel/PR, v. 2, n. 1, p. 1-13, jan./abr. 2008.

MELCHIOR, José Carlos de Araújo. A política de vinculação de recursos públicos e o financiamento da educação no Brasil. São Paulo: FEUSP, 1981.

OLIVEIRA, R. O financiamento da educação. In: ; ADRIÃO, Theresa (Org.). Gestão, financiamento e direito à educação: análise da Constituição Federal e da LDB. 3. ed. São Paulo: Xamã, 2007. p. 83-122.

PINTO, José Marcelino de Resende. Os recursos para a educação no Brasil no contexto das finanças públicas. Brasília: Plano, 2000.

ROSSINHOLI, Marisa. Política de financiamento da educação básica no Brasil: do FUNDEF ao FUNDEB. Brasília: Liber Livro, 2010.

Recebido 07/10/2017

Aceito: 11/10/2017.

Como citar este artigo (Formato ABNT):

AMORIM, Célia Maria F. G. O planejamento como instrumento de gestão eficaz e eficiente: Uma análise do sistema educacional no município de Iguatu. Id on Line Revista Multidisciplinar e de Psicologia, 2017, vol.11, n.38, p. 80-89. ISSN: 1981-1179.

Recebido: 29.09.2017

Aceito: 09.11.2017 